The Version of Record of this manuscript has been published and is available in Aging \& Mental Health (2016) http://www.tandfonline.com/doi/full/10.1080/13607863.2016.1179261

\title{
The use of the truth and deception in dementia care amongst general hospital staff
}

Alex Turner, Fiona Eccles, John Keady, Jane Simpson and Ruth Elvish

Corresponding author: Ruth Elvish

School of Nursing, Midwifery and Social Work, University of Manchester,

Manchester M13 9PL UK Tel: +44 (0)1670 676240 Email: ruth.elvish@googlemail.com

Alex Turner

Doctorate in Clinical Psychology, Division of Health Research, Lancaster University, Lancaster, LA1 4YG, UK Tel: +44 (0)7988758738 Email: alexturner21@ hotmail.co.uk

Fiona J R Eccles

Doctorate in Clinical Psychology, Division of Health Research, Lancaster University, Lancaster, LA1 4YG, UK Tel: +44 (0)1524 592807 Email: f.eccles@lancaster.ac.uk

John Keady

School of Nursing, Midwifery and Social Work, University of Manchester,

Manchester M13 9PL UK Tel: +44 (0)161 3067854 Email: john.keady@ manchester.ac.uk

Jane Simpson

Doctorate in Clinical Psychology, Division of Health Research, Lancaster University, Lancaster, LA1 4YG, UK Tel: +44(0)1524 592858 Email: j.simpson2@lancaster.ac.uk

Acknowledgements: Professor Ian James

Word count: 4,990 


\begin{abstract}
Objectives: Deceptive practice has been shown to be endemic in long-term care settings. However, little is known about the use of deception in dementia care within general hospitals and staff attitudes towards this practice. This study aimed to develop understanding of the experiences of general hospital staff and explore their decision-making processes when choosing whether to tell the truth or deceive a patient with dementia.
\end{abstract}

Method: This qualitative study drew upon a constructivist grounded theory approach (Charmaz, 2006) to analyse data gathered from semi-structured interviews with a range of hospital staff. A model, grounded in participant experiences, was developed to describe their decision-making processes.

Findings: Participants identified particular triggers that set in motion the need for a response. Various mediating factors influenced how staff chose to respond to these triggers. Overall, hospital staff were reluctant to either tell the truth or to lie to patients. Instead, 'distracting' or 'passing the buck' to another member of staff were preferred strategies. The issue of how truth and deception are defined was identified.

Conclusion: The study adds to the growing research regarding the use of lies in dementia care by considering the decision-making processes for staff in general hospitals. Various factors influence how staff choose to respond to patients with dementia and whether deception is used. Similarities and differences with long-term dementia care settings are discussed. Clinical and research implications include: opening up the topic for further debate, implementing staff training about communication, and evaluating the impact of these processes. 
Key words: dementia, deception, truth-telling, general hospital, staff.

\section{Introduction}

It is estimated that 35.6 million people worldwide live with dementia, which typically, but not exclusively, affects individuals over the age of 65 (Prince et al., 2013). In the UK, approximately $5 \%$ of people over 65 live with dementia and by the age of 80 that prevalence increases to approximately 20\% (Department of Health, 2009). Dementia is a syndrome that often includes memory loss, a decline in functional ability and difficulties with communication (World Health Organisation [WHO], 2012).

The challenges associated with supporting people with dementia are well documented (Brodaty, Draper, \& Low, 2003; Edberg et al., 2008). It is common for people with dementia in the mid to later stages of the disease, owing to changes in memory, to become 'timeshifted'. People are often shifted back to an emotional time in their past in which they think something needs to be resolved or attended to (eg. find their partner; visit a sick relative; collect small children from school; get to work to support their family). When such ideas are triggered, the person strongly believes their view. Hence, at such times a truth (eg. your partner is dead, your children are grown up) will be viewed with incredulity and likely perceived by the person as an attempt to deceive. In these kinds of situations, care staff find themselves in an uncertain position in which they must decide whether to tell the truth or use a lie.

The topic of deception and truth-telling within dementia care has received much attention in recent decades. A number of years ago, a UK study found that $96 \%$ of care staff reported using lies when caring for residents with dementia (James, Wood-Mitchell, Waterworth, Mackenzie, \& Cunningham, 2006). This is consistent with studies undertaken in other countries (Hertogh, Mei The, Miesen, \& Eefsting, 2004; Tuckett, 2004), although it has 
also been found that staff are uncomfortable with acknowledging the use of deception in their work (Cunningham, 2005; Hasselkus, 1997).

Recent years have seen arguments for and against the use of deception within dementia care settings; these draw from ethical, person-centred and practical standpoints (for a more detailed outline of these arguments see Elvish, James, \& Milne, 2010). The literature to date has included debate on the types of situations in which deception might be used, for example to ease distress, and there have been numerous explorations about what constitutes a lie (e.g. Blum, 1994; Cunningham, 2005; Hasselkus, 1997). There has been a steady growth of evidence to support the use of lies if they are used in the best interests of a person with dementia and when other strategies have been unsuccessfully applied (Cunningham, 2005; Day, James, Meyer, \& Lee, 2011; Elvish et al., 2010; James et al., 2006). However, the topic remains controversial, with a recent review highlighting that there is currently little agreement amongst carers, practitioners or people living with dementia on the ethical acceptability of the use of deception in dementia care (Mental Health Foundation, 2014).

The care of people with dementia in general hospitals is an area that has received much attention in recent years. Up to $25 \%$ of general hospital beds are occupied by people with dementia and more than $97 \%$ of general hospital staff report having cared for patients with dementia (Alzehimer's Society, 2009). Despite this, dementia training and education amongst general hospital staff is poor (Moyle, Borbasi, Wallis, Olorenshaw, \& Gracia, 2010) and there is a lack of confidence in managing behaviour that challenges amongst this staff group (Atkin, Holmes, \& Martin, 2005). Similarly to care home staff, it is likely that general hospital staff face conundrums about whether to use the truth or deception, for example, when a person with dementia believes it is 1970 and they need to get home to cook tea for their husband. To our knowledge, there are no studies to date that explore the use of deception amongst general hospital staff. The current study therefore aimed to gather an 
understanding of the views and experiences of staff within general hospital settings regarding the use of truth and deception when caring for people with dementia. In particular, it aimed to explore their decision making processes when choosing whether to tell the truth or to deceive. A grounded theory (GT) methodology was used to construct a model of this process, grounded in participants' accounts (Charmaz, 2006).

\section{Method}

Two NHS Trusts within North-West England agreed to participate in the study. It was reviewed by Lancaster University Faculty of Health and Medicine Research Ethics Committee and given a favourable opinion by Lancaster University Research Ethics Committee. Approval to undertake the project was given by the Research and Development Offices from the two participating NHS Trusts.

The study drew upon a constructivist GT methodology, based primarily on Charmaz's (2006) approach. More traditional GT approaches adopt a realist perspective (e.g. Glaser \& Strauss, 1967), suggesting there are objective truths that are testable and verifiable. In contrast, a constructivist approach to GT suggests no objective reality exists (Mills, Bonner, \& Francis, 2006) and instead attempts to construct an interpretation of participants' perceived reality.

\section{Interview procedure}

The initial interview schedule was developed using findings from previous research regarding deception in dementia care primarily in long-term care settings (e.g. Cunningham, 2005), with initial areas of interest or 'sensitizing concepts' (Blumer, 1969) being developed. Initial questions included 'Is there a time when you have considered lying to a patient with dementia?' and 'What helped you make the decision?'. Using a semi-structured approach ensured questions could be modified in light of responses from participants; the role of the 
interviewer was to guide, rather than dictate, the direction of the interview. Following coding of initial interviews, the interview schedule was adapted to pursue possible gaps in the data. For example, additional questions included 'Are there times when you feel that deceiving patients is more acceptable?'. After the interview, participants were given the opportunity to raise any questions and all were provided with a debrief form. All interviews were digitally recorded and transcribed verbatim. Interview length ranged between 36 and 65 minutes.

\section{Sampling and participants}

Thirteen general hospital wards on which patients were predominantly over the age of 65 were targeted for recruitment. A total of 12 participants were recruited from 8 wards. Participants were staff members with direct experience of working with patients with dementia (for the purposes of this study we did not identify aspects such as the stage or types of dementia of which the participants had experience). All pariticpants were fluent in English.

In line with GT methodologies (Charmaz 2006), a theoretical sampling strategy was adopted. Six interviews were initially undertaken with a staff nurse, two support workers, two housekeeping staff and a ward clerk. Further participants were then recruited based on particular characteristics, such as job role, to explore ideas that had emerged as part of the ongoing process of constant comparative analysis and theory development. The second phase of interviews comprised a ward manager, a ward sister, a physiotherapist, a medical doctor, a support worker and a student nurse. Ten participants were female, and the median length of time working within older people's wards was 13 years. Ten participants defined themselves as White British, one as White Irish and one as Indian British.

\section{Data analysis}

Initially, transcribing interviews and re-reading transcripts generated familiarity with the data (Bird, 2005). Charmaz (2006) identified GT as an iterative process, whereby 
analysis and sampling take place concurrently. Therefore, the first author (AT) began the coding stage of analysis while continuing with data collection. The first stage of 'open coding' summarised participant accounts in line by line detail.

Following open coding, codes that were considered more frequent or significant were combined to produce 'focussed codes'. Focussed coding allowed AT to separate, sort and synthesise the data, explaining larger segments of transcript (Charmaz, 2006). Charmaz (2006) recommends moving from focussed coding directly to the process of raising conceptual categories. However, she also emphasises that the approach is not prescriptive and allows for flexibility. The researcher therefore chose to include an additional level of analysis, arguably similar to the' theoretical coding' described by Glaser and Strauss (1965, 1967). This helped to identify similarities, differences and links between the focussed codes and to identify the conceptual relationships between developing categories.

In order for ideas to be explored, analysis was done in stages using a 'constant comparative method' (Charmaz, 2006; Glaser \& Strauss, 1967). Initially, the first six interviews were analysed as described. During this stage, data was compared both within and between those first few interviews. As theory developed and similarities and contradictions in the data were identified, this informed further investigation in subsequent interviews. By theoretically sampling participants in this way, the emergent theory could be continually probed, refined and 'tested' against the data (Charmaz, 2006). Additionally, memos were recorded throughout the data collection process, developing ideas or observations that were considered relevant to AT and to the relationships in the data. In the later stages of analysis, memos also helped to develop more abstract and analytical concepts in the emerging theory (Tweed \& Charmaz, 2011). This analytic process formed the basis of the model shared in this article. 


\section{Credibility of analysis}

To ensure credibility of the analysis, recommendations on conducting qualitative research were employed (Elliot, Fischer, \& Rennie, 1999; Yardley, 2008). In order to show sensitivity to existing work (Yardley, 2008), the study used previous literature to help generate a relevant research question. Participants were recruited with consideration of this research question and any ethical implications. To ensure credibility checks were completed (Elliot et al. 1999), the first author (AT) and two further authors (RE and JK) carried out initial coding on the first two transcripts. The codes were compared with those of AT to ensure consistency regarding interpretation of the data. Where there were any inconsistencies in interpretation, this was discussed further until a consensus was reached. Additionally, after the first four interviews, the emerging theoretical model was discussed amongst all authors to ensure it remained grounded in the data. While participant validation can be an element of GT, a pragmatic decision was made not to include it, given the limited time and resources available for the size of this project and the time constraints for participants.

\section{Findings}

Figure 1 represents the decision-making process of staff when choosing whether to deceive patients with dementia. Within this process, 'triggers' set in motion the need for a response. Various 'mediating factors' influence how staff 'respond' to these triggers. However, in specific situations, participants might have to 'adapt their desired response'.

\section{INSERT FIGURE 1 ABOUT HERE}

\section{Triggers}

Participants described three types of situation where the use of deception might be considered: i) in response to difficult questions (e.g. asking for a deceased relative); ii) when 
attempting to manage behaviour that challenges or provide personal care (e.g. refusing to accept medication or trying to leave the ward); and iii) when sharing medical information (e.g. discussion about diagnosis, discharge plans and end of life care).

When faced with these 'triggers', staff were required to make a decision of how to respond; this process was influenced by a number of 'mediating factors'.

\section{Mediating Factors}

Poor communication and lack of guidance: A key mediating factor was lack of communication amongst staff. All participants reported that they had never openly discussed the use of deception with their colleagues. Non-qualified staff felt that more formal discussion would provide clarity around what they were expected to do in difficult situations. However, these participants did not feel comfortable raising the topic for discussion. Participants with a more senior role acknowledged that whilst they did not always tell the truth themselves, they were uncomfortable directing other staff to deceive for fear of leaving themselves open to blame: “Even though I might sometimes do it, I wouldn't feel comfortable telling others to... it's their job, their PIN number...we are all accountable for our own actions" (Ward Sister, 130).

Discussion about the use of deception was also considered challenging because time and resources provided little opportunity for all staff to be involved in necessary discussions. Moreover, a number of participants were not routinely invited to formal information sharing opportunities where these discussions could potentially be initiated. As one housekeeper explained: "I don't get included, so I don't get the opportunity to ask for advice." (217). This lack of communication prompted staff to independently evaluate how best to respond in a given situation, many choosing to do what they thought was best until they were told to do otherwise. 
Staff interpretations of role/responsibility and 'knowing the person': All participants discussed the importance of developing trust and relationships with the patients they cared for in order to know how best to respond. Having relevant and accurate information about a patient was also deemed necessary. However, participants identified obstacles within their job roles that made these things difficult to achieve. A distinction was particularly evident between qualified and non-qualified staff. Although non-qualified staff spent large amounts of time with patients, they felt they didn't really have appropriate information about them:

Even though we spend most of the time with them, day in day out, we don't really get to hear anything about them....you just have to pick up what you can...and if it's coming from them [patients], you don't know if it's true (support worker, 75).

Additionally, most non-qualified staff did not consider it their responsibility to cause potential upset: “I don't know if I should be the one to upset them...I don't think I'm in the best position to do that" (Housekeeper, 316).

Interestingly, qualified nurses who had access to handover and patient documentation described themselves as too busy to spend quality time with patients and build good relationships. Although they had more information about the patient, they felt they did not have capacity to support them if they became distressed: "If what I said upset them, I don't have time to sit with them and make them feel better, there's just too much other stuff to do" (Staff Nurse, 211). Paradoxically, this meant both qualified and non-qualified participants believed the other to be in a better position to tell the truth.

Finally, the doctor and physiotherapist also believed that others were in a better position to give potentially upsetting news (unless something directly concerned a medical issue). Their sporadic time on the ward meant they did not have opportunity to form relationships and they were not made privy to personal information. 
In summary, the overarching finding within this factor was that responding truthfully to certain trigger situations was often considered 'somebody else's job'.

Referring to ethical framework: The third mediating factor involved staff assessing a situation against a framework of ethical conduct. Again, this was often influenced by whether the participant was a non-qualified or qualified member of staff. For non-qualified staff, responses were generally governed by 'personal ethics'; their own moral beliefs of what was right and wrong. Non-qualified staff tended to focus upon what were termed moral dilemmas, such as whether a deceased relative was coming. In these situations, many non-qualified staff responded to patients based upon the rule of treating others as you would want to be treated. However, this often left staff in a conundrum rather than helping them to make a clear decision about how to respond. For example, many suggested that their personal ethics prevented them from wanting to cause distress but also prevented them from wanting to 'lie': "I think it's probably wrong to lie about something like that [death of relative], but at the same time, if I was to tell the truth, it would upset them loads. I just couldn't do that" (Ward Clerk, 20).

Qualified participants appeared to give less concern to moral dilemmas, instead referring to situations where they might be considered unprofessional if they were to give the 'wrong' response. Specific examples were concerned with administering medication or discussing diagnoses and end of life care. In these situations, participants were generally clear on when they would and would not deceive. For example, a qualified nurse participant suggested they would "lie through their teeth... and drop it in their tea" (Ward Sister, 227) to ensure patients took the correct medication. However, adhering to their professional code of ethics led staff to remain truthful when discussing diagnosis or end of life care. 
Regardless of the ethical framework underpinning their decision, all staff suggested that the response given was done so in what they perceived to be the patient's best interests.

\section{Responding}

As depicted in Figure 1, participants predominantly relied upon four types of response: telling the truth, passing the buck, distracting or lying.

Telling the Truth. While most participants considered truth-telling to be theoretically the right option, when faced with 'triggers' this was generally the least preferable response. Participants often felt that their relationship with the patient, their responsibilities on the ward, and their ethical framework made it inappropriate for them to respond truthfully.

"Passing the Buck". For non-qualified staff, "passing the buck" to qualified staff enabled them to maintain their position of not wanting to cause distress or resort to the use of lies: 'I'll often say 'I'm not sure if he's [husband] coming, we can ask the nurse when she comes" (Housekeeper, 79). In this way, staff felt they were offering a form of support to patients without having to provide a concrete answer. Similalry, the doctor and physiotherapist also often chose to pass responsibility: "I'm here for ward-round, then I'm off somewhere else...I leave those kinds of questions to the nurses" (Doctor, 75). For qualified nurses therefore, "the buck" often stopped with them.

Distracting. For all participants, distracting patients was considered the most favourable response as it did not require using outright lies or causing potential upset. However, distraction was often a time consuming process and was not always successful. It was in these cases that the use of a lie was considered.

Lying. Qualified staff were most likely to lie, particularly to ensure medication was taken, using professional ethical guidelines to inform their decision: "It's about remembering 
why we are telling these porkies...it's $\mathrm{OK}$ as long as we maintain those boundaries of when to tell that little fib" (Ward Sister, 427).

Interestingly, as the above quotation suggests, participants were reluctant to describe their response as lying, no matter how inaccurate the information. There were a number of different terms used such as "telling a little white lie", "humouring the patient", "bending the truth" or "going along with it".

\section{Adapting Desired Response}

In most cases, the mediating factors described encapsulated the decicion-making process. However, it was felt that desired responses needed to be adapted if an interaction was observed by relatives or when a patient showed significant distress or agitation. Adapted responses have been considered separately from other mediating factors because they appear to intervene with the usual decision-making process.

When observed by relatives, the majority of participants suggested they were more likely to give the perceived 'socially acceptable' response of telling the truth, often believing that they could trigger a complaint if they used deception.

Conversely, participants suggested they were more likely to lie when faced with a patient who was significantly distressed or agitated. This was often based upon experience of patients becoming physically aggressive and concern for the safety of other patients on the ward. In these situations, it was considered more important to calm patients down in whatever way possible. 


\section{Discussion}

The present study adds to the growing research regarding the use of lies in dementia care; to our knowledge it is the first study which explores this topic within a general hospital setting.

The overarching finding from the study was a lack of clarity amongst staff about how to respond, alongside a feeling of being unable to accept the responsibility to do so.

Generally, participants suggested that they would prefer not to lie. However, they were equally reluctant to tell the truth.

\section{Lack of communication and guidance}

Irrespective of position or experience on the ward, no participants felt able to discuss the use of deception with their colleagues; this was despite the finding that non-qualified staff felt that more discussion around the use of deception would be helpful. Interestingly, qualified staff appeared more reluctant than non-qualified staff to initiate or support deception, for fear of being left open to blame. This is in contrast to a study by James et al. (2003) which found that $83 \%$ of staff in care home settings felt comfortable telling their managers about the lies they told. Through various pieces of work, particularly that of the Newcastle Challenging Behaviour Service in the North-East of England, the acknowledgement of the use of lies within care homes has been established for some years. Our study suggests that lack of open discussion about deception amongst general hospital staff mirrors the experience of care home staff in previous years.

\section{Role and responsibility}

The sense of 'paralysis' about whether to tell the truth or a lie to people with dementia was further encapsulated in the theme of 'role and responsibility'. 
Much research discusses the importance of knowing the person with dementia (Cunningham, 2005; Day et al., 2011; Kitwood \& Bredin, 1992); however, non-qualified participants in the present study suggested that they had difficulty obtaining knowledge about their patients. This left them feeling that they did not have the information to make an accurate judgement about whether they were telling the truth or using deception, leaving them unsure of how to respond.

Interestingly, both qualified and non-qualified staff perceived the other to be in a 'better position' to tell the truth. Non-qualified staff did not feel it was their responsibility to cause upset. Conversely, qualified staff considered themselves too busy to build up good therapeutic relationships or spend time with patients should they become distressed following an interaction with a member of staff.

These findings pose an apparent conundrum amongst general hospital staff about who is better placed to respond: those with factual information about the person or those with a good relationship with the person.

\section{Ethical frameworks}

Personal ethical frameworks also left staff uncertain about how to respond, whereas professional ethical frameworks appeared to provide the most clarity about whether to tell the truth or a lie.

Non-qualified staff found that personal ethical frameworks left them confused: many used the rule of "treating others as you would want to be treated" and felt that if the truth would cause upset then it should be avoided. However, many had longstanding beliefs that "lying is wrong", which left them also wanting to avoid deception. 
Rather than using personal ethical frameworks, qualified staff tended to refer to professional ethical guidelines. They made reference to the four principals of bioethics: beneficence, non-maleficence, autonomy, and justice (Beauchamp \& Childress, 2009), which appeared to enable them to be clearer on instances of when they would tell the truth or lie.

No matter what ethical framework participants used, all suggested that their responses were given in the best interests of the patient. This corroborates a number of previous studies suggesting that lies are used only in the best interests of the person with dementia (Cunningham et al., 2005; Day et al., 2011; Elvish et al., 2010; James et al., 2006; Tuckett, 2012).

\section{Responses and definitions of lying}

In line with previous research (eg. (Blum, 1994; Cunningham, 2005; Hasselkus, 1997), the current study provides further data for the debate about what should be defined as deception and lying. We themed our data into four categories: telling the truth, distracting, passing the buck and lying.

Distracting was generally identified as the preferred option, as participants believed this response was neither the truth nor a lie. For non-qualified staff, 'passing the buck' was also found to be a preferred option. Similarly to distracting, this reduced the need to either tell the truth or a lie. The category of 'passing the buck' does not seem to have been identified within research undertaken in other dementia care settings. Whilst passing the buck could be considered a form of avoidance (a commonly identified response within the literature, see Cunningham, 2005; Day et al., 2011), we would argue that it merits consideration in its own right. Our data suggests that this response was specifically related to handing responsibility for a response over to another member of staff and it may be evident within a general hospital setting due to hierarchical staff structures and clearly defined roles. 
On the rare occasions that participants reported lying, they did so believing it to be consistent with their ethical frameworks. However, deceptive practices were often reframed using expressions such as telling "little fibs" or "bending the truth". Using such terms possibly helped to reduce cognitive dissonance, given that lying seemed to be considered "wrong" overall from a personal perspective (Cunningham, 2005; Festinger, 1962), even if it could be justified with the use of an ethical framework.

\section{Adapting desired response}

Our findings suggest that personal ethical frameworks such as "lying is wrong" become particularly salient when relatives are present, suggesting that staff believe that relatives are likely to hold similar ethical frameworks to themselves and, as such, judge deception as as wrong. As the final part of the model, this finding encapsulates well the overall finding within the study that there is lack of clarity within practice in a number of ways for this staff group.

\section{Clinical implications}

As discussed, there was an overwhelming sense of paralysis amongst staff about how to respond when faced with a situation in which they could use the truth or deception with a person with dementia. This was caused by the identified factors and ethical frameworks which sometimes contradicted and overrode each other, for example, a staff member may deem that lying is in a person's best interest but they may then feel the need to tell the truth in the presence of relatives due to personal ethical frameworks. Our findings suggest that nonqualified staff would welcome further guidance on the topic. However, qualified staff seem reluctant to 'open up' the issue. Much work has already been undertaken in care home settings to put the topic of deception on the table: studies have found that training which incorporates discussion about lies in dementia care results in staff being more likely to define 
their practice as deception and has led to people being more accepting towards the use of lies (Elvish, et al., 2010). Guidelines around how to approach the use of deception in dementia care settings have also been developed (Culley, Barber, Hope, \& James, 2013; James et al., 2006). However, as was previously the case in long-term care environments, our study suggests that deception with people with dementia remains a taboo subject amongst general hospital staff. Our findings suggest that replicating the processes that have been undertaken within dementia care home settings would be beneficial within general hospital environments. This would fit well with the person-centred nursing framework proposed by McCormack and McCance (2006), which identifies the importance of care staff gaining clarity about their own values and 'knowing themselves'. Given the sense of paralysis about how to respond per se amongst general hospital staff, we would suggest that the best starting point for training programmes in general hospitals would be to initially focus on communication, the truth and deception (eg. Elvish et al., 2014).

The current study also identified the need for better information sharing. Potential options to facilitate this include staff handover time or specific staff information sessions. This would provide opportunity for all staff members to discuss individual patients and encourage consistency. This would also help to ensure that patient best interests are considered collaboratively.

It is hoped that our findings may add to the Dementia and Truth-Telling inquiry that is currently being undertaken by the Mental Health Foundation, a piece of work which is likely to have a significant impact on the future of this topic in years to come.

\section{Future research}

In order to develop the findings from this study, we would propose that work undertaken previously within dementia care home settings should be further replicated within 
general hospital environments. Further research should focus on opening up the debate about the use of the truth and deception within a general hospital environment. Larger studies should enable more generalizable knowledge to be gained about the use of deception in general hospitals, and research looking at the impact of training on staff attitudes towards the use of lies should be undertaken. Tools such as the 'Attitudes towards Lying to People with Dementia' questionnaire (Elvish et al., 2010) would benefit from further psychometric analysis within such studies.

\section{Limitations}

The current study was conducted within a limited geographical area of the UK. It would therefore be beneficial to explore practice on a much larger scale to identify whether staff use similar decision-making processes and hold similar attitudes in general hospital settings elsewhere.

Secondly, certain staff groups were under-represented due to recruitment difficulties. Both the doctor and the physiotherapist provided interesting data. However, because they varied from other participants in a number of ways e.g. their limited time on the ward and both being male, it is difficult to unpick exactly how their job roles impacted upon decisionmaking. Unfortunately, it proved challenging to find more professionals in similar roles willing to take part in the current study.

\section{Conclusion}

This study adds to the growing research regarding the use of lies in dementia care. Staff in general hospital settings are often unclear about whether to use the truth, a lie, or "something else"; leaving them in an uncertain place when trying to decide how to respond to a patient with dementia. Various factors influence their decision-making process, but these 
factors can often leave them in a conundrum rather than providing them with clear guidance on how to respond. Many staff would welcome further discussion on the issue and it is hoped that future work within research and clinical practice will lead to further exploration of the use of deception within dementia care in general hospitals. 


\section{References}

Alzheimer's Society (2009). Counting the Cost: Caring for People with Dementia on Hospital Wards. Retrieved from www.alzheimers.org.uk/site/scripts/download.php?fileID $=787$

Atkin, K., Holmes, J., \& Martin, C. (2005). Provision of care for older people with co-morbid mental illness in general hospitals: general nurses' perceptions of their training needs. International Journal of Geriatric Psychiatry, 20, 1081-1083. doi: 10.1002/gps.1414

Beauchamp, T., \& Childress, J. (2009). Principals of Biomedical Ethics. New York: Oxford University Press.

Bird, C. M. (2005). How I stopped dreading and learned to love transcription. Qualitative Inquiry, 11(2), 226-248. doi: 10.1177/1077800404273413

Blum, N. S. (1994). Deceptive practices in managing a family member with Alzheimer's disease. Symbolic Interaction, 17(1), 21-36. doi: 10.1525/si.1994.17.1.21

Blumer, H. (1969). Symbolic Interactionism. Englewood Cliffs, NJ: Prentice-Hall.

Brodaty, H., Draper, B., \& Low, L. (2003). Nursing home staff attitudes towards residents with dementia: strain and satisfaction with work. Journal of Advanced Nursing, 44(6), 583-590. doi: 10.1046/j.0309-2402.2003.02848.x

Charmaz, K. (2006). Constructing grounded theory: A practical guide through qualitative analysis. London: Sage.

Culley, H., Barber, R., Hope, A., \& James, I. (2013). Therapeutic lying in dementia care. Nursing Standard, 28(1), 35-39. doi:10.7748/ns2013.09.28.1.35e7749 
Cunningham, J. (2005). Care staff views about telling the absolute truth to people with dementia. Doctoral Dissertation in Clinical Psychology. UK: Ridley Building, Newcastle upon Tyne.

Day, A., James, I., Meyer, T., \& Lee, D. (2011). Do people with dementia find lies and deception in dementia care acceptable? Aging \& Mental Health, 15(7), 822-829. doi: $10.1080 / 13607863.2011 .569489$

Department of Health (2009). Living well with dementia: A national dementia strategy. Retrieved from https://www.gov.uk/government/uploads/system/uploads/attachment_data/file/168220 /dh_094051.pdf

Edberg, A., Bird, M., Richards, D., Woods, R., Keeley, P., \& Davis-Quarrell, V. (2008). Strain in nursing care of people with dementia: Nurses' experience in Australia, Sweden and United Kingdom. Aging and Mental Health, 12(2), 236-243. doi: $10.1080 / 13607860701616374$

Elliot, R., Fischer, C., \& Rennie, D. (1999). Evolving guidelines for publication of qualitative research studies in psychology and related fields. British Journal of Clinical Psychology, 38(3), 215-229. doi: 10.1348/014466599162782

Elvish, R., Burrow, S., Cawley, R., Harney, K., Graham, P., Pilling, M.,...Keady, J. (2014). 'Getting to know me': The development and evaluation of a training programme for enhancing skills in the care of people with dementia in general hospital settings. Aging \& Mental Health, 18(4), 481-488. doi: 10.1080/13607863.2013.856860

Elvish, R., James, I., \& Milne, D. (2010). Lying in dementia care: An example of a culture that deceives in people's best interests. Aging \& Mental Health, 14(3), 255-262. doi: $10.1080 / 13607861003587610$ 
Feil, N. (1993). The validation breakthrough: Simple techniques for communication with people with “Alzheimer's type dementia”. Baltimore, MD: Health Professions Press.

Festinger, L. (1962). A theory of cognitive dissonance. California: Stanford University Press.

Glaser, B. G., \& Strauss, A. L. (1965). Awareness of Dying. Chicago: Aldine.

Glaser, B. G., \& Strauss, A. L. (1967). The Discovery of Grounded Theory: Strategies for Qualitative Research. Chicago: Aldine.

Hasselkus, B. R. (1997). Everyday ethics in dementia care: Narratives of crossing the line. Gerontologist, 37(5), 640-649. doi: 10.1093/geront/37.5.640

Hertogh, C. M., The, B. A., Miesen, B. M., \& Eefsting, J. A. (2004). Truth telling and truthfulness in the care for patients with advanced dementia: An ethnographic study in Dutch nursing homes. Social Science \& Medicine, 59(8), 1685-1693. doi: 10.1016/j.socscimed.2004.02.015

James, I. (2011). Understanding behaviour in dementia that challenges: A guide to assessment and treatment. London: Jessica Kingsley Publishers.

James, I. A., Powell, I., Smith, T., \& Fairbairn, A. (2003). 'Lying to residents: Can the truth sometimes be unhelpful for people with dementia?' PSIGE Newsletter, BPS 82, 2628.

James, I. A., Wood-Mitchell, A., Waterworth, A. M., Mackenzie, L., \& Cunningham, J. (2006). 'Lying to people with dementia: developing ethical guidelines for care settings'. International Journal of Geriatric Psychiatry, 21(8), 800-801. doi: 10.1002/gps. 1551

Kitwood, T., \& Bredin, K. (1992). Towards a theory of dementia care: Personhood and wellbeing. Aging \& Society, 12(3), 269-287. doi: 10.1017/S0144686X0000502X 
Mental Health Foundation. (2014). Dementia - What is truth? Retrieved from http://www.mentalhealth.org.uk/content/assets/PDF/publications/dementia-enquirylit-review.pdf

Mills, J., Bonner, A., \& Francis, K. (2006). Adapting a constructivist approach to grounded theory: Implications for research design. International Journal of Nursing Practice, 12, 8-13. doi: 10.1111/j.1440-172X.2006.00543.x

Moyle, W., Borbasi, S., Wallis, M., Olorenshaw, R., \& Gracia, N. (2010). Acute care management of older people with dementia: A qualitative perspective. Journal of Clinical Nursing, 20, 420-428. doi: 10.1111/j.1365-2702.2010.03521.x

McCormack, B., \& McCance, T. V. (2006). Development of a framework for person-centred nursing. Journal of Advanced Nursing, 56(5), 472-479.

Prince, M., Bryce, R., Albanese, E., Wilmo, A., Ribeiro, W., \& Ferri, C. (2013). The global prevalence of dementia: A systematic review and meta-analysis. Alzheimer's Dementia, 9(1), 63-75. doi: 10.1016/j.jalz.2012.11.007

Tweed, A., \& Charmaz, K. (2011). Grounded theory for mental health practitioners. In A. Thompson \& D. Harper (Eds.), Qualitative research: An introduction to methods and designs (pp. 41-67). San Francisco: Jossey-Bass.

Tuckett, A. (2012). The experience of lying in dementia care: A qualitative study. Nursing Ethics, 19(1), 7-20. doi: 10.1177/0969733011412104

Wood-Mitchell, A., Cunningham, J., Mackenzie, L., \& James, I. (2007). Can a lie ever be therapeutic? The debate continues. Journal of Dementia Care, 15(2), 24-28. doi:10.1002/gps.1551.

World Health Organisation (2012). Dementia: A public health priority. Retrieved from http://www.who.int/mental_health/publications/dementia_report_2012/en/ 
Yardley, L. (2008). Demonstrating Validity in Qualitative Psychology. In J. A. Smith (Ed.)

Qualitative Psychology: a practical guide to research methods (pp. 235-252).

London: Sage. 
Figure 1: Theoretical model of decision-making process

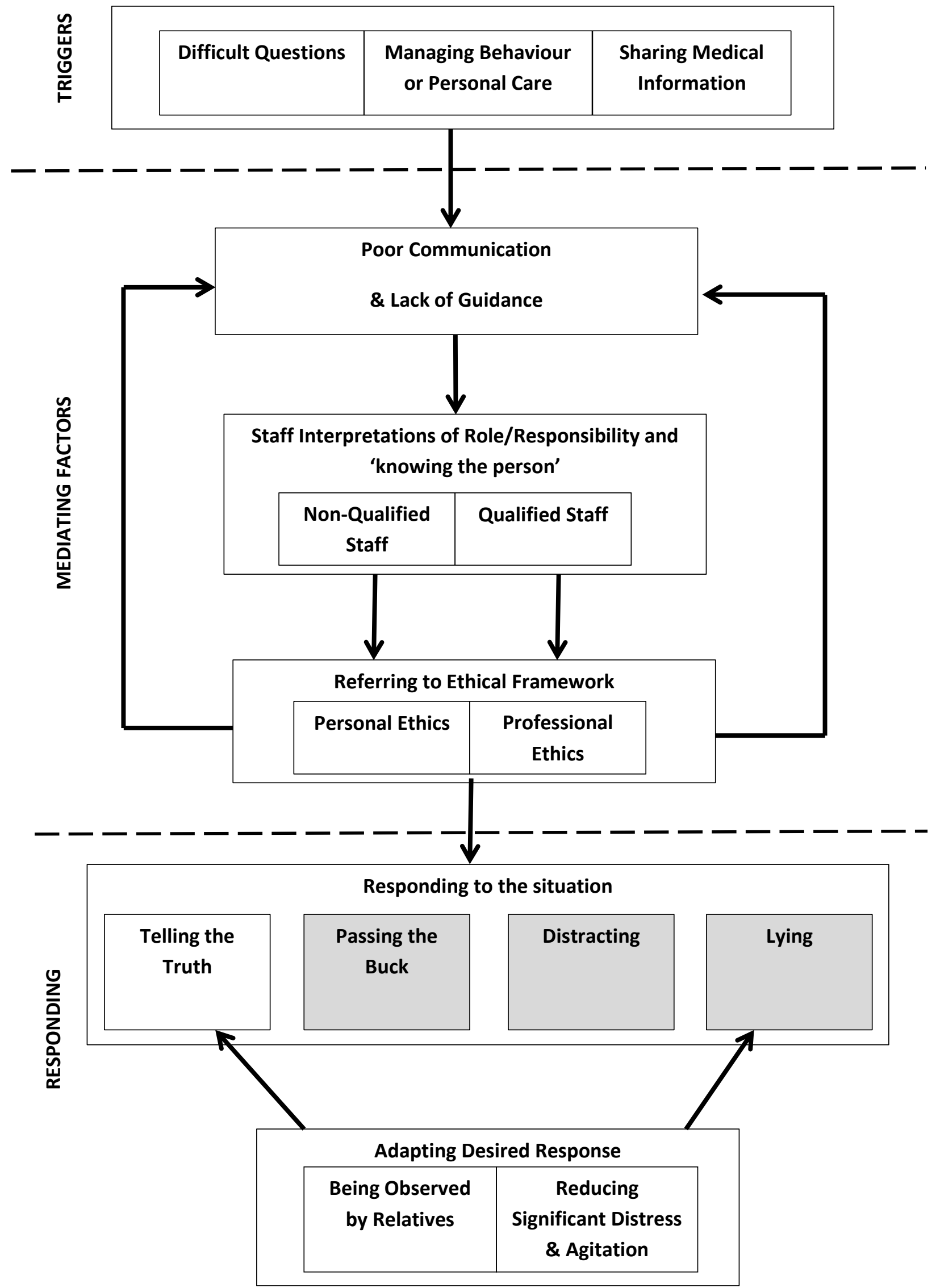


